\title{
EXPERIMENTAL AND THEORETICAL STUDIES OF SOLVATION OF IONS
}

\author{
Charles D. Jonah and Yi Lin \\ Chemistry Division, Argonne National Laboratory
}

Solvents determine the outcome of many industrial chemical reactions. Sometimes small changes in the properties of the solvent system can have dramatic consequences on the economics of these processes, and a broad array of empirical analyses have been performed to evaluate solvent effects on chemical processes. Chemists at Argonne National Laboratory have adopted a very direct approach and are measuring the actual rates of solvation of large organic anions in different solvents for the first time. Chuck Jonah and Yi Lin used the Argonne linac to create the anions in an unsolvated state, and then studied the manner in which they interacted with surrounding molecules. They showed that anion solvation occurs at a much faster rate than had been predicted, and they provided a theoretical understanding of the way in which the reaction rates intimately depend upon the chemical structures of the solvents. These experiments, which provide new insight into this important aspect of chemistry, were carried out by Charles D. Jonah and Yi Lin of the Argonne National Laboratory Chemistry Division using the Argonne picosecond linac and the stroboscopic pulse radiolysis system. This work was carried out with funding from the Division of Chemical Sciences, Office of Basic Energy Sciences.

\section{DISCLAIMER}

This report was prepared as an account of work sponsored by an agency of the United States Government. Neither the United States Government nor any agency thereof, nor any of their employees, makes any warranty, express or implied, or assumes any legal liability or responsibility for the accuracy, completeness, or usefulness of any information, apparatus, product, or process disclosed, or represents that its use would not infringe privately owned rights. Reference herein to any specific commercial product, process, or service by trade name, trademark, manufacturer, or otherwise does not necessarily constitute or imply its endorsement, recommendation, or favoring by the United States Government or any agency thereof. The views and opinions of authors expressed herein do not necessarily state or reflect those of the United States Government or any agency thereof.
RECEIVED FEB 281996 OSTI

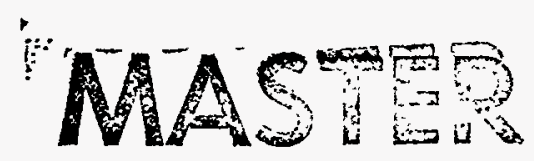




\title{
EXPERIMENTAL AND THEORETICAL STUDIES OF SOLVATION OF IONS
}

\author{
Charles D. Jonah and Yi Lin \\ Chemistry Division, Argonne National Laboratory
}

Solvation has long been known to be an important factor in determining chemical reactivity. However, until recently, it was not possible to measure the rates of solvation. In the last few years, laser experiments have made it possible to measure solvent kinetics, albeit for rieutral rather than charged species. Because many reactions take place between charged species, it is clear that it is necessary to see if the solvation kinetics of ions are the same as for uncharged species. Until we began our measurements there had been no measurements of anion solvation at room temperature.

The solvation of the benzophenone anion was measured in a series of primary and secondary alcohols using the Argonne picosecond linac. The benzophenone anion was formed from the reaction of the presolvated electron with the benzophenone molecule. This reaction takes place in less than $20 \mathrm{ps}$. We then observe the solvation of the anion by the change in the optical spectrum as a function of time. Typical results are given in Figures $1 \mathrm{a}$ and $1 \mathrm{~b}$. These figures show the shift of the spectrum of the benzophenone anion as a function of time in n-octanol and 2-octanol. The shift is quite clear. What also should be noted is the difference in the amount of spectral shift in 2-octanol compared to 1-octanol. The amount of shift is much greater in 1-octanol than in 2-octanol.

The rates for the benzophenone-anion solvation in different solvents are given in Figure 2. The solvation time is plotted against the dielectric relaxation time - a time that describes the rate at which the solvent molecules rearrange. Included in the figure are the time necessary for the solvation of the electron in different alcohols that were measured earlier at Argonne and the solvation of dipoles (formed by creating an excited state with a laser) that have been measured by other workers. What is interesting is that the solvation of the electron and the solvation of the anion are very similar whereas the dipole solvation is much slower. One might have thought that the quantum particle, the electron, would be the different one; however that does not appear to be the case. Clearly solvation is different for anions. 
The difference in wavelength shift between primary and secondary alcohols provides further insight into the solvation process. Simple continuum theory would suggest that the amount of solvation, measured by wavelength shift, would depend on the dipole density. However, the amount of shift is very similar for propanol to decanol, whereas the dipole density changes by a factor of 3 ; conversely, the dipole density is the same for 1- and 2- octanol but the spectrum shifts. These results suggest that a microscopic effect is important. A simple model of a solvent molecule was made that could give the geometrical properties of a primary alcohol, a secondary alcohol, and a molecule like a primary alcohol but with the dipole moment reversed (something like acetonitrile). Figure 3 shows the results of a Monte Carlo simulation. The solvation energy is much larger for the primary alcohol-like model, smaller for the secondary-like, and smallest for the acetonitrile-like model. The origin of the effect is the interference between adjacent molecules for the secondary alcohol, leading to less solvation.

This work has provided a new pathway for understanding solvation. We will pursue both new experiments and new theoretical techniques. We will alter the structure of the probe molecule (the benzophenone anion) to understand the interrelation between solvent and solute structure and solvation time. We will change the temperature to vary the internal energy of the system.

Our theoretical studies will emphasize more realistic models. We will use quantum mechanical models to evaluate the correspondence between solvation energy and spectral shift. These calculations will also give significant insight into the approximations that are used in calculating solvation. 
FIGURE CAPTIONS

Figure 1. Spectra of the benzophenone radical anion in (a) 1-octanol and (b) 2-octanol at different times. These figures show that the maximum of the final solvated benzophenone ion is further blue in 1-octanol and in 2-octanol, showing more solvation of the anion in 1-octanol.

Figure 2. The experimental solvation time for the solvated electron, for the benzophenone anion and for different excited dipoles as a function of the relaxation rate of the solvent - the dielectric relaxation time.

Figure 3. The solvation energy of an anion in three model solvents - one intended to simulate a primary alcohol, one to stimulate a secondary alcohol, and the third to simulate acetonitrile. These results were calculated using Monte Carlo calculations. 

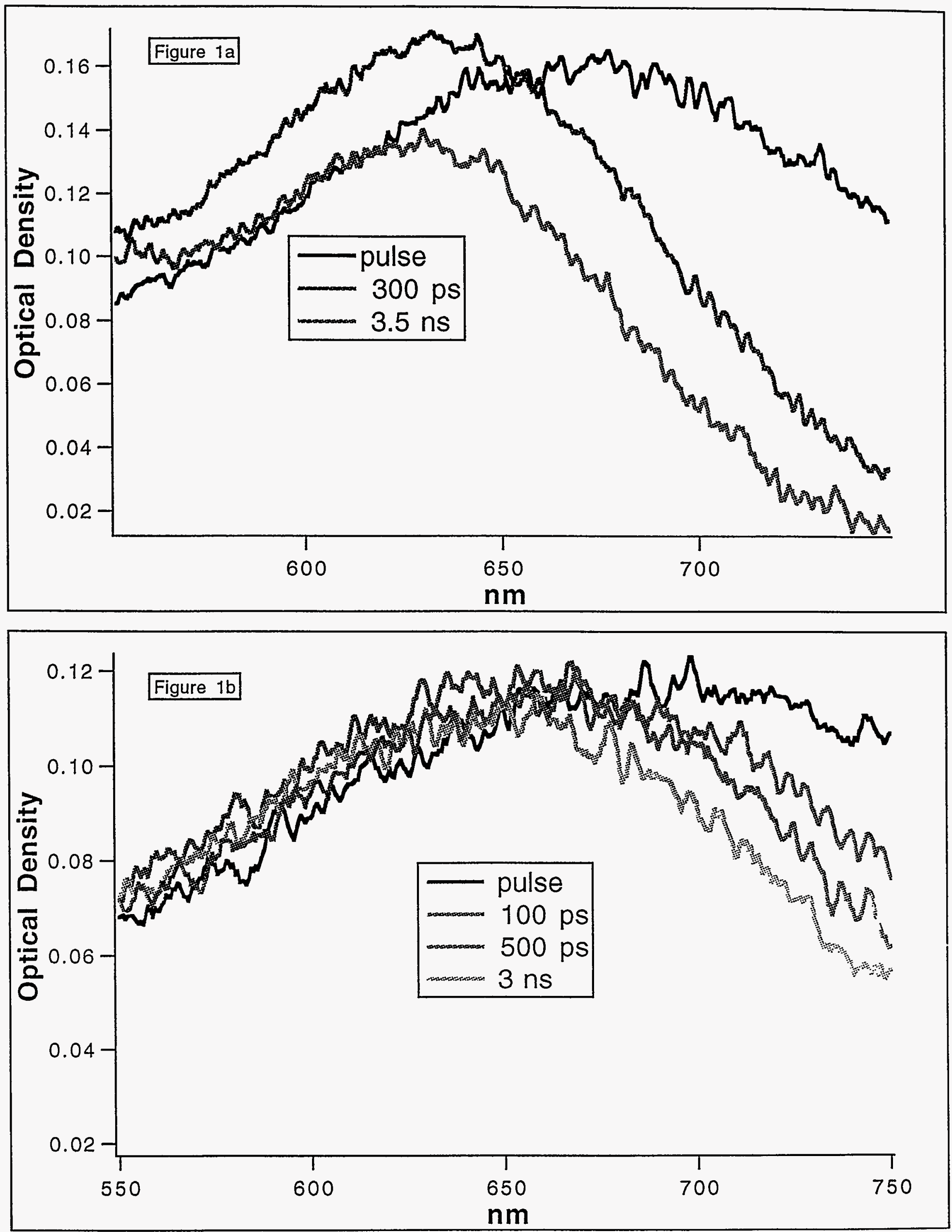


\section{Solvation time $v s$. Longitudinal relaxation time}

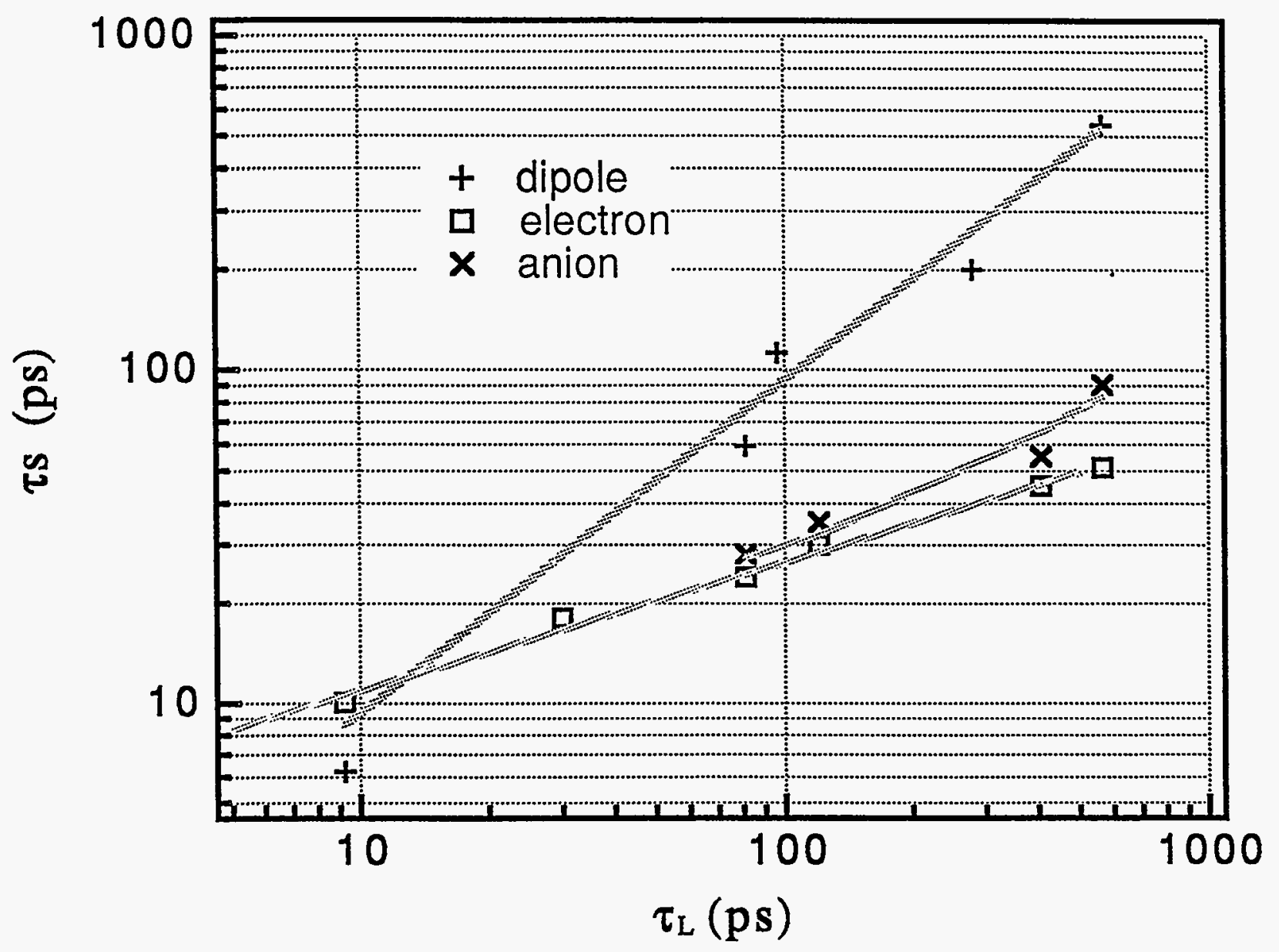

"Lines are added to guide the eye 


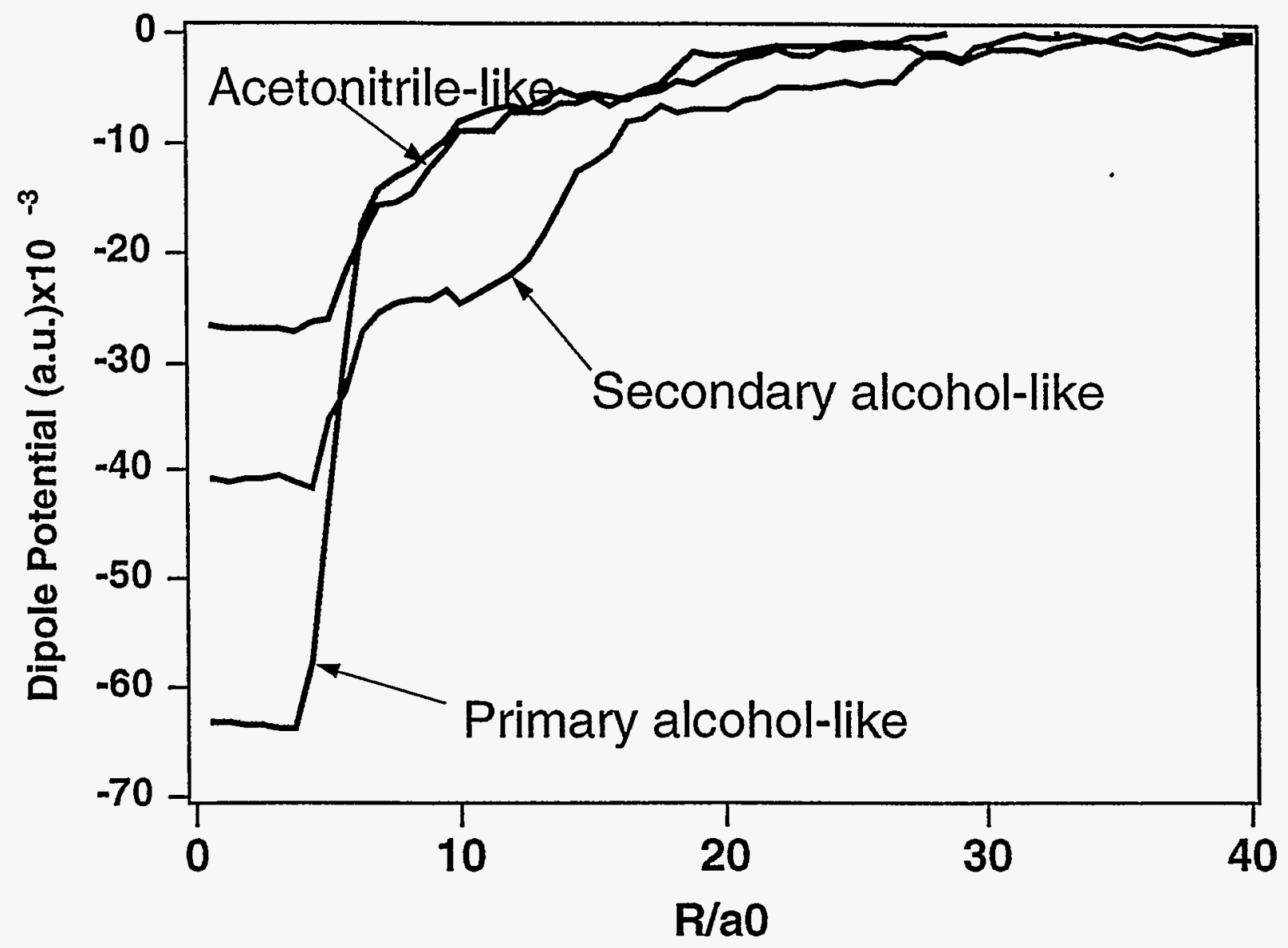

